\title{
Gendered Experiences in Developmental Pathways to Crime: Editorial Introduction
}

\author{
T. R. McGee $^{1} \cdot$ P. Mazerolle ${ }^{1}$
}

Published online: 24 September 2016

(C) Springer International Publishing AG 2016

Keywords Gender - Crime · Developmental and Life-Course · Criminology · Female . Pathways

\section{Background: Examining Gender in Developmental Pathways to Crime}

The study of developmental pathways to crime and criminal behaviour across the life-course does not enjoy a long history in the field of criminology. It is only recently, over the past few decades, that researchers have engaged and advanced our thinking and understanding of more dynamic, developmental theoretical and empirical models of offending behaviour over time and across the life-course (for example, [3, 5, 6, 8]). However, exploring gender and crime, and the female offender more particularly, dates to an earlier period of criminology [4]. Despite the fact that early and more modern attempts to fully capture and understand gender and offending were largely inadequate for several reasons including by being under-theorised, under-conceptualised and under-examined, opportunities existed for researchers to engage with these issues. The fact they chose not to in large number illustrates too well that the focus and indeed early priorities of nineteenth and twentieth century criminologists were on the crime problems generated by males (and largely studied by males). Indeed, it is well documented that criminological theory and the models developed to predict, explain and understand processes of offending have been predominantly about male patterned behaviour. Approaches to

\section{T. R. McGee}

tr.mcgee@griffith.edu.au

P. Mazerolle

p.mazerolle@griffith.edu.au

1 Griffith Criminology Institute, Griffith University, Brisbane, Australia 
applying and explaining processes for females, when considered, were often not about capturing unique differences or processes, but rather identifying similar processes, with less exposure to common risks regardless of gender [1].

The story around the rise of developmental and life-course criminology, as it relates to exploring gendered pathways has followed a similar trajectory. Early theories, conceptions and models were disproportionality applied to male offending patterns and dimensions across the life-course. Justifications at the time revealed concern about the absence of females in the early onset, life-course persistent or chronic offender categories [7], where more serious criminal careers were unfolding. A notable exception is Daly's [2] examination of female pathways to felony court which while developmental in nature focused more on feminist theory than developmental and life-course criminological theories.

While it is true that studies of developmental processes and offending across the life-course are still disproportionally focused on male offending, the tide is starting to change. The fact that data sets are increasingly becoming available that include both male and female offenders across the life-course and that enable further research is important but so too is the increased awareness of the need to explore developmental processes for females. There is an increasing need and recognition of the need to explore gendered pathways to offending across the life-course. Indeed, the reasons for exploring gender and developmental pathways to crime and criminal behaviour have never been more important and cut to the core of what is foundational about the field. Clearly, the maturity of the field of developmental and life-course studies requires a re-consideration of the current partiality of knowledge. For the field to advance, a greater consideration of both common and uncommon developmental pathways to crime across the life-course is required. This is no easy task, for it requires a full appreciation of the nature of criminal careers, a commitment to measure and assess gender differentiation and a commitment to understand how gender can shape these processes.

Beyond partial knowledge is the inadequacy and completeness of extant theory. Theories of the developmental processes shaping crime across the life-course are still in their relative infancy when one considers the role of gender. While understandable, it is clear that for knowledge to advance, much greater attention to theoretical innovation will be required to fully appreciate how processes are shaped by gender and understood across the life-course. In short, our theories require enlivening through the lens of gender to be fully complete.

Finally, we need to expand knowledge of gendered risks, precursors and processes of offending, not only for shaping our understanding of offending behaviour but also for informing our preventative responses to crime. Interventions aimed at preventing and controlling crime are still evolving in terms of their precision in addressing criminogenic risks and processes that relate to gender. It is accepted that a number of key risks are gender invariant; however, this must not detract from the fact that mechanisms of prevention and effective interventions can be experienced or shaped for males and females in ways that maximise their efficacy. This means that effective interventions for both males and females across the life-course may well be best served by combinations of interventions that address general risks as well as interventions that address gendered differentiated risks. In the end, this requires a more fulsome commitment to research, to examine and to evaluate a range of these topics. 


\section{Overview of the Special Issue}

This special issue forms the first of a two-part special issue focussing on gendered experiences in developmental pathways to crime. We were overwhelmed with the interest as reflected in the volume of submissions as well as the quality of the work. Consequently, special issues examining gendered experiences in developmental pathways to crime will appear in 2016 and 2017. In short, this special issue which includes six excellent papers and forming a comprehensive volume in its own right is only part of the whole picture.

In this first special issue, a truly international picture is provided with research and data drawn from the USA, Canada, Sweden and The Netherlands. The included papers employ sophisticated methodological procedures and illustrate a range of quantitative, qualitative and mixed method approaches. Importantly, the papers provide a logical coherence tackling various stages of the life-course. For example, the first four papers focus on pathways into offending at various stages of the life-course, from childhood, through adolescence, into adulthood. The final two papers examine post-conviction desistence and recidivism.

In the first paper, Ahonen, Jennings, Loeber and Farrington examine data from the Pittsburgh Girls Study to explore the relationship between self-reported offending (theft and violence) and officially recorded police charges. Using data from ages 11-18, three trajectories of self-reported offending were identified: non-offenders, low-rate offenders and high-rate offenders. Their examination of the police charges for each of these groups showed that the mean number of police charges in the highrate self-reported offending group was five times higher than the overall mean number of charges. The identification of this small group of high-rate, versatile, persistent female offenders, using self-report data, is a unique contribution to developmental criminology. The authors call for further research examining the predictors of membership of this group.

Pasko and Chesney-Lind examine six young women who have a history of commercial sexual exploitation, and their paper forms the second paper of this special issue. The researchers conducted three waves of in-depth interviews with each of the women, approximately 6 months apart. At the time of the last interview, all of the women were on probation or parole. The life histories of the young women reveal the interaction of negative family experiences and commercial sexual exploitation with the onset and escalation of offending. Detailed narratives provide the stories that illuminate and explain the development of offending observed in large longitudinal data sets, with a specific focus on the role of commercial sexual exploitation. These young women view their normative aspirations for education, employment and housing as inaccessible and instead are caught in harmful cycles of family instability, violence, drug addiction, residential instability, educational failure and commercial sexual exploitation. The authors draw attention to the importance of trauma-informed programming for engaging with the events that lead these young women into offending.

Continuing on the theme of exploring the early life experiences of women on the pathway to offending, Simpson, Alper, Dugan, Horney, Kruttschnitt and Gartner report on their analyses of the Women's Experience of Violence Study. Using a life event calendar methodology, the researchers gathered retrospective life history information of female offenders in the Baltimore City Detention Center $(n=351)$, the Hennepin 
County Adult Detention Center in Minnesota $(n=205)$ and the Ontario's Vanier Center for Women $(n=248)$. The authors undertook a comparison of the predictors of different ages of onset to discover that an early onset of offending is associated with childhood sexual abuse, sexual precocity, low supervision and lack of childhood bonds. Adult onset offenders, however, who make up $43 \%$ of the sample, are characterised by an absence of these risk factors. The authors call for further research exploring the mechanisms that explain adult onset for female offenders.

In the next paper, Joosen, Palmen, Kruttschnitt, Bijleveld, Dirkzwager and Nieuwbeerta explored similarities and differences between male and female offenders incarcerated in Dutch prisons. Males and females were found to be similar in terms of their engagement in property offences, running away from home prior to age 16, their parents' deviance when they were children, being homeless and receiving state benefits, but their paper also highlights some important differences. The authors conducted latent class trajectory analysis of the gender-specific data sets and found similar latent classes in both the male and the female samples. These groupings are interpreted in the context of Daly's (1992) descriptions of different types of male and female offenders. Despite these observed similarities, the authors note that "even in the context of seemingly similar pathways into crime, the gendered lives of women and men may be linked to differences in the timing and the fallout from exposure to various risk factors."

A shift in focus is observed in the fifth paper, by Kerrison, Bachman and Paternoster, which examines pathways away from crime by exploring patterns of desistence in a sample of 224 women who were initially incarcerated for drug-related offences in the early mid-1990s. The authors employ the arrest histories of these women, from 1989 to 2008 , to generate latent class trajectories of offending. Multinominal logistic regression analyses show that being older at age of release (for the baseline offence) was the only factor that predicted desisting group membership (compared to those who persisted). Follow-up in-depth interviews with a stratified random sample of women drawn from each of the five trajectory groups generated themes and storylines which the authors have linked into the themes of employment, parenting, romantic relationships and substance abuse. The findings are interpreted in the context of the identity theory of desistence.

In the final paper in this issue, Sivertsson explores recidivism in a large sample of males $(n=27,071)$ and females $(n=7531)$ from a Swedish birth cohort study. His analyses showed that females were less likely to be reconvicted after their first and second convictions. However, as females' convictions accumulate over the life-course (5-9 convictions), they are more likely to be reconvicted than males. The findings raise questions about whether this increase in reconviction probability can be explained by state dependence or population heterogeneity processes linking past and future offending. While this debate cannot be resolved in the context of the paper, it does provide researchers with further information on important patterns of female recidivism. Overall, for both males and females, this study showed that the likelihood of recidivism decreases over time.

As stated earlier, we were overwhelmed with the response of researchers seeking to contribute to this special issue on gender and developmental pathways to crime across the life-course. With a large volume of excellent papers, we will deliver an additional special issue in 2017. While this response was somewhat unexpected, it may 
well indicate some emerging and pleasing trends toward the expanding interest in research on developmental pathways to crime across the life-course for females.

At the same time, it is important to place this special issue in context. Knowledge about patterns of female offending, compared to males, is still in its relative infancy. However, the papers in this volume illustrate that exploring developmental paths to offending for females is an important issue on its own merits. In short, comparisons to male patterns are informative, but the maturity of research in this area will increasingly see female-specific approaches standing on their own merits and terms.

Finally, it is worth commenting that we view the field of developmental and lifecourse criminology as a rich and vibrant one, but whereby a comprehensive knowledge base around precursors, patterns, and processes over time are still emerging. While new studies have filled gaps in knowledge, they inevitably illuminate new needs for further areas on inquiry. This is indeed magnified when increasingly sophisticated explanatory models are applied employing data gathered from throughout the world. At the same time, the examination of gender and developmental pathways to crime is an illustration of the importance of particularizing the knowledge about offending processes over time. Clearly, there is much more effort required to build an expanded knowledge base about developmental offending patterns across the life-course and across various domains of interest such as gender, race/ethnicity and social-economic disadvantage among other areas. This special edition of the Journal of Developmental and LifeCourse Criminology reflects one important contribution toward the important purpose of building a more comprehensive knowledge base of developmental patterns of offending across the life-course.

\section{References}

1. Broidy, L. M., \& Agnew, R. (1997). Gender and crime: a general strain theory perspective. Journal of Research in Crime \& Delinquency, 34(3), 275-306.

2. Daly, K. (1992). Women's pathways to felony court: feminist theories of lawbreaking and problems of representation. Southern California Review of Law and Women's Studies, 2(11), 11-52.

3. Farrington, D. P. (2005). The Integrated Cognitive Antisocial Potential (ICAP) Theory. In D. P. Farrington (Ed.), Integrated developmental and life-course theories of offending: advances in criminological theory (Vol. 14, pp. 73-92). New Brunswick: Transaction.

4. Lombroso, C., \& Ferrero, G. (1893/2004). Criminal woman, the prostitute, and the normal woman (N. H. Rafter \& M. Gibson, Trans.). Durham, NC: Duke University Press.

5. Moffitt, T. E. (1993). Adolescence-limited and life-course-persistent antisocial behavior: a developmental taxonomy. Psychological Review, 100(4), 674-701.

6. Sampson, R. J., \& Laub, J. H. (1993). Crime in the making: pathways and turning points through life. Cambridge: Harvard University Press.

7. Silverthorn, P., \& Frick, P. J. (1999). Developmental pathways to antisocial behaviour: the delayed-onset pathway in girls. Development and Psychopathology, 11, 101-126.

8. Thornberry, T. P. (1987). Toward an interactional theory of delinquency. Criminology, 25(4), 863-892. 